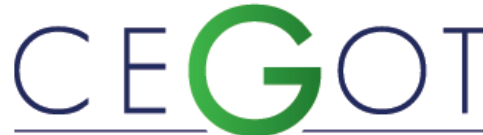

Centro de Estudos de Geografia e Ordenamento do Território
Faísco, ANA

Universidade de Évora - Escola de Ciências e Tecnologia,

Departamento de Geociências

7000-671, Évora, Portugal

anabiafaisco@gmail.com

\section{SIMPLÍCIO, DOMINGAS}

Universidade de Évora - Escola de Ciências e Tecnologia,

Departamento de Geociências

7000-671, Évora, Portugal

domingas@uevora.pt

\section{CARMo, ANDré}

Universidade de Évora - Escola de Ciências e Tecnologia, Departamento de Geociências, Centro Interdisciplinar de Ciências Sociais (CICS.NOVA.UÉvora)

7000-671, Évora, Portugal

acarmo@uevora.pt

\title{
Enoturismo e Desenvolvimento Local: Reguengos de Monsaraz, Cidade Europeia do Vinho 2015
}

Wine Tourism and Local Development: Reguengos de Monsaraz, European Wine City 2015

Referência: Faísco, Ana; Simplício, Domingas; Carmo, André (2021). Enoturismo e Desenvolvimento Local: Reguengos de Monsaraz, Cidade Europeia do Vinho 2015. Revista de Geografia e Ordenamento do Território (GOT), n.o 21 (Junho). Centro de Estudos de Geografia e Ordenamento do Território, p. 290-310, dx.doi.org/ 10.17127/got/2021.21.012

\section{RESUMO}

O enoturismo, setor do turismo caracterizado por deslocações realizadas com a motivação de visitar e conhecer adegas e regiões vitivinícolas, contribui para promover o desenvolvimento local, tem vindo a assumir, nos últimos anos, uma maior importância para as regiões vitivinícolas. A Cidade Europeia do Vinho (CEV), é uma iniciativa internacional de cariz enoturístico, promovida pela Rede de Cidades Europeias do Vinho (RECEVIN), que contemplou já várias regiões vitivinícolas, incluindo, em 2015, Reguengos de Monsaraz. Esta iniciativa provocou um conjunto de impactos para os produtores de vinho, para a comunidade e para o território, que serão objeto de análise neste artigo.

Palavras-chave: Enoturismo; Cidade Europeia do Vinho 2015; Reguengos de Monsaraz; Desenvolvimento Local.

\section{ABSTRACT}

Wine tourism, a tourism sector characterized by trips made with the motivation of visiting and getting to know wineries and wine regions, is considered as a marketing tool and a way to promote local development and has assumed greater importance for wine regions in 
recent years. The European Wine City (CEV), is an international wine tourism initiative, promoted by the Network of European Wine Cities (RECEVIN), which has already contemplated several wine regions, namely, Reguengos de Monsaraz, in 2015. This initiative caused several impacts, for wine producers, for the community and for the territory, that will be analysed in this article.

Keywords: Wine tourism; European Wine City; Reguengos de Monsaraz; Local Development.

\section{Introdução}

O enoturismo é um fenómeno que tem vindo a ganhar importância crescente na configuração dos territórios, designadamente ao nível da relevância que assume enquanto alavanca para o desenvolvimento local a partir de um produto (vinho) em torno do qual se projetam inúmeras outras experiências sócio-territoriais. Não existindo uma definição única para esta atividade ela é aqui entendida, na esteira de Hall et al (2000, p.247), sobretudo enquanto "visitas a vinhas, adegas, festivais vitivinícolas e eventos do vinho e da uva nos quais se prova o vinho e/ou se experienciam os atributos de uma região vitivinícola", formulação genérica e integradora que não anda longe daquela que tem sido veiculada pela principal autoridade nacional para o setor do turismo, o Turismo de Portugal.

Este fenómeno tem atraído, em Portugal, cada vez mais visitantes e novos produtores, verificando-se uma evolução positiva das atividades enoturísticas e de produção de vinho. Em 2018, por exemplo, visitaram Portugal 2,5 milhões de turistas atraídos pelo enoturismo, levando a um aumento de cerca de 300 mil face ao ano de 2016.

O enoturismo é de grande importância para as regiões vitivinícolas porque favorece a sua promoção e desenvolvimento, contando-se, entre os seus principais contributos, o alargamento dos mercados e o aumento das vendas para os proprietários das adegas, o incremento do emprego, a dinamização do tecido económico local e o aumento do rendimento para os residentes (Getz, 2000; Brás, 2010). Mais do que uma motivação para a realização de viagens, esta atividade parece assumir-se como um fator de desenvolvimento, quer para as unidades vitivinícolas, permitindo chegar a novos públicos, quer para a economia de uma região vitivinícola que se pode afirmar, através de uma estratégia adequada, enquanto destino turístico. 
Com este artigo pretende-se, a partir da análise do caso de Reguengos de Monsaraz, Cidade $^{1}$ Europeia do Vinho 2015 (CEV2015), explorar os impactos do enoturismo para o desenvolvimento local considerando que este assenta, normalmente, em duas estratégias: o empreendedorismo local, aqui representado pelos produtores de vinho e pelas empresas ligadas ao enoturismo, e a capacidade de atração de investimentos externos através da competitividade local e do marketing.

$\mathrm{Na}$ esteira de Braga (2002, p.26), para quem o desenvolvimento local "seria um desenvolvimento "de baixo para cima" porque o controle dos processos econômicos e das decisões de investir estaria nas mãos dos atores locais, sejam eles públicos ou privados", a perspetiva adotada nesta pesquisa também procura colocar em evidência o papel desempenhado pelos diferentes atores que intervêm no território investigado.

Embora existam trabalhos que abordam os contributos e desvantagens do enoturismo para as comunidades, produtores e desenvolvimento das regiões vitivinícolas (Macionis, 1998; Getz, 2000; Skinner, 2000; Costa e Dolgner, 2003; Carlsen, 2004; Bento, 2017; Lucena, 2017; Nunes, 2018), os impactos locais da Cidade Europeia do Vinho (CEV), nomeadamente em Portugal, não foram ainda objeto de investigação específica numa ótica eminentemente geográfica. O estudo de caso, presente nesta investigação, assentou em duas componentes. A primeira - pesquisa documental - consistiu na recolha, tratamento e análise de dados provenientes de fontes secundárias, destacando-se o site oficial da Rede Europeia de Cidades do Vinho (RECEVIN) ${ }^{2}$, o Dossier de Candidatura de Reguengos de Monsaraz a CEV2015³ , o Balanço das atividades da CEV2015 e dados disponibilizados pelo IVV4. Esta etapa permitiu não só compreender o que é a iniciativa CEV, mas perceber melhor o caminho que levou à candidatura de Reguengos de Monsaraz a CEV2015.

A segunda componente integrou a aplicação de um inquérito, por questionário, e a realização de entrevistas semi-estruturadas, para perceber os impactos da CEV2015 e as

10 termo "cidade" é meramente simbólico, não se referindo efetivamente a quaisquer divisões políticas, administrativas ou estatísticas do território.

2 Rede Europeia das Cidades do Vinho. Disponível em http://www.recevin.eu/. Acesso em: 20 de abril de 2020.

3 Município de Reguengos de Monsaraz. Disponível em http://www.cm-reguengosMonsaraz.pt/pt/Paginas/home.aspx. Acesso em: 24 de abril de 2020.

4 Instituto da Vinha e do Vinho. Disponível em https://www.ivv.gov.pt/np4/home.html. Aceso em: 24 de abril de 2020. 
eventuais mudanças que o evento provocou no concelho. Os questionários e guiões de entrevista apresentaram uma estrutura semelhante, constituída por duas partes distintas: uma focada na CEV2015, incidindo a outra nos impactos percecionados pelos inquiridos/entrevistados durante o ano daquela iniciativa. Foram inquiridos 50 munícipes e realizadas quatro entrevistas a representantes de adegas/parceiras da iniciativa CEV2015 e ao Presidente da Câmara Municipal de Reguengos de Monsaraz. A este respeito, importa sublinhar que as perturbações causadas pela pandemia limitaram as opções metodológicas à disposição da equipa de investigação, sobretudo no que diz respeito à recolha de dados primários.

A seleção de Reguengos de Monsaraz prende-se não só com o facto de este município ser conhecido pela produção vitivinícola, pela qualidade e diversidade dos seus vinhos e pelo peso que esta atividade assume na sua economia, como pela importância que a vinha e o vinho têm na identidade do município. Ao procurar perceber de que forma a CEV2015 influenciou Reguengos e contribuiu para o seu desenvolvimento, a partir de uma análise eminentemente exploratória desta iniciativa, sua génese, desenvolvimento e impactos, pretende-se também refletir sobre a importância do enoturismo e dos seus benefícios para as regiões vitivinícolas, em sentido lato.

\section{O Enoturismo enquanto fenómeno geográfico}

A ligação entre a sociedade e o vinho tem raízes ancestrais que se prendem ao cultivo da vinha e à produção de vinho, fundadas numa cultura mediterrânea que, com o passar do tempo, se enraizou nos hábitos e culturas de muitos países, sendo neste contexto que surge o enoturismo. Como sugere Hall (2000), apesar da relação entre o turismo e vinho ser antiga, o pleno desenvolvimento do enoturismo só aconteceu a partir do início do século XX, quando foi reconhecido como fenómeno autónomo, de motivações próprias e com capacidade de satisfazer os interesses culturais. O enoturismo revela-se como uma tentativa de aprendizagem, afirmação e valorização individual e cultural, onde o vinho, concebido como uma forma de prazer tradicional representando a ligação entre a sociedade e o passado, se associa à prática do turismo, assumindo-se, assim, como uma combinação entre o território, a cultura e as tradições locais. 
Por sua vez, para Getz (2000), o enoturismo é uma "viagem" de interesse especial, baseada no particular desejo de visitar regiões vitivinícolas, ou decorrentes de viagens realizadas por outros motivos, nas quais a principal motivação dos turistas não é o vinho. Esta perspetiva, introduz a possibilidade de os praticantes desta atividade serem turistas cuja principal motivação da viagem não sendo o vinho, acabam por se aproximar dele enquanto referência para a construção das suas experiências turísticas.

Pelo que já se referiu, esta atividade só é possível em regiões vitivinícolas que apresentem grande área de cultivo de vinha, muitos produtores de vinho, elevado volume de produção bem como um conjunto importante de infraestruturas de suporte para as adegas. Para além disso, a reputação dos vinhos, a existência de empresas vitivinícolas orientadas para receber enoturistas, a promoção de eventos em torno do vinho, a articulação do enoturismo com a proteção dos recursos paisagísticos e patrimoniais e a existência de serviços e equipamentos de apoio às múltiplas atividades geradas através da cultura vitivinícola são outros fatores importantes a considerar (Getz et al, 1999; Getz, 2000; Var et al, 2006; Inácio, 2008).

Refira-se que o enoturismo apresenta um leque bastante diversificado de impactos (Tabela 1), destacando-se, pela positiva, a criação de empregos, a atração de turistas, o aumento do consumo de produtos locais ou a captação de novos investimentos e oportunidades de negócio que, em conjunto, podem contribuir para a revitalização sócio-territorial num sentido amplo; por outro lado, o desenvolvimento de dinâmicas de exclusão e marginalização de determinados grupos sociais, a descaracterização identitária dos territórios ou a degradação ambiental são alguns aspetos negativos a considerar.

Como produto turístico, o enoturismo só é capaz de funcionar em pleno se houver um esforço de diversas entidades (Abreu e Costa, 2002). Só assim se poderá valorizar o contacto direto do turista com as atividades vitivinícolas e com todo o património paisagístico e arquitetónico relacionado com a cultura da vinha e a produção do vinho. Particularmente relevante, a este respeito, são as rotas do vinho, que constituem um instrumento fundamental na ligação entre turismo e produção de vinho. De facto, como defende Williams (2001), como destino turístico, a viabilidade das regiões vitivinícolas a longo prazo depende da implementação de políticas regionais que tornem sustentáveis as paisagens vitivinícolas. 
Tabela 1 - Impactos do Enoturismo.

\begin{tabular}{|c|c|c|}
\hline & Positivos & Negativos \\
\hline $\begin{array}{l}\text { População } \\
\text { residente }\end{array}$ & $\begin{array}{l}\text { Criação de eventos e atividades; } \\
\text { Criação de novos empregos; } \\
\text { Criação ou melhoria de infraestruturas; } \\
\text { Enriquecimento cultural; } \\
\text { Experiência e contacto com turistas; } \\
\text { Orgulho local; } \\
\text { Preservação e valorização dos valores } \\
\text { culturais, das tradições, da autenticidade e } \\
\text { identidades locais; }\end{array}$ & $\begin{array}{l}\text { Deterioração das condições de emprego; } \\
\text { Especulação imobiliária; } \\
\text { Exclusão social; } \\
\text { Marginalização dos habitantes locais; } \\
\text { Perda de identidade local. }\end{array}$ \\
\hline $\begin{array}{c}\text { Produtores } \\
\text { de vinho }\end{array}$ & $\begin{array}{l}\text { Atração de novos mercados; } \\
\text { Aumento das vendas; } \\
\text { Aumento dos lucros; } \\
\text { Criação de novas parcerias; } \\
\text { Novas fontes de rendimento; } \\
\text { Promoção da marca e sua fidelização. }\end{array}$ & $\begin{array}{l}\text { Deterioração dos terrenos agrícolas devido } \\
\text { à sobrecarga turística; } \\
\text { Perda de propriedade das vinhas. }\end{array}$ \\
\hline $\begin{array}{l}\text { Território/ } \\
\text { Destino } \\
\text { turístico }\end{array}$ & $\begin{array}{l}\text { Atenuação da sazonalidade; } \\
\text { Atração de novos visitantes; } \\
\text { Aumento do número de turistas; } \\
\text { Aumento do gasto médio por visitante; } \\
\text { Captação de novos investimentos; } \\
\text { Consolidação da marca/ imagem do destino; } \\
\text { Incrementação do consumo de produtos } \\
\text { locais; } \\
\text { Promoção da sustentabilidade ambiental; } \\
\text { Revitalização de atividades económicas } \\
\text { tradicionais. }\end{array}$ & $\begin{array}{l}\text { Aumento do tráfego; } \\
\text { Degradação ambiental; } \\
\text { Descontrolo da procura e comercialização; } \\
\text { Desgaste dos caminhos/ estradas; } \\
\text { Poluição dos solos. }\end{array}$ \\
\hline
\end{tabular}

Fonte: Elaborado pelos autores partir de Getz (2000), Skinner (2000) e Carlsen (2004)

Note-se que apesar das vantagens que o enoturismo apresenta para as indústrias vitivinícolas, alguns viticultores resistem em apostar nesta atividade devido ao investimento financeiro necessário para desenvolver infraestruturas e formar recursos humanos, e por recearem que a atração de turistas e o aumento de vendas dos vinhos não seja suficiente para amortizar o investimento efetuado (Hall, 1997). A falta de interesse por parte de alguns produtores pelo enoturismo, deve-se também ao facto de o entenderem como uma atividade secundária da qual apenas beneficiam marginalmente.

Por último, mesmo considerando o enoturista como "alguém que tem o desejo de provar vinho e experimentar o espaço geográfico onde o vinho é produzido" (Byrd et al, 2016, p.20), não pode deixar de colocar-se em evidência o facto de existirem diversas experiências enoturísticas que são indissociáveis dos perfis do visitante. Assim, para Hall e Macionis (1998) existem três tipos de enoturistas que se distinguem pelo grau de interesse no vinho: os amantes (wine lovers), os interessados (wine interested) e os curiosos (wine curious). Por seu lado, Charters e Ali-Knight (2002) apresentam uma proposta mais desagregada, 
considerando cinco grupos: amantes, interessados, curiosos, peritos (connoisseur, turistas detentores de elevados conhecimentos sobre vinho e interessados no mesmo, que procuram aprender mais sobre a produção vitivinícola) e penduras (hanger-on - pessoas que não tendo interesse sobre vinho, fazem parte de um grupo que decidiu fazer uma viagem cuja principal motivação é o vinho). À luz destes exemplos fica claro que os enoturistas constituem um grupo diversificado de pessoas que varia em função de atributos tais como a idade, a ocupação ou a classe social. Importa, assim, que cada região vitivinícola conheça o tipo de turista predominante bem como as suas necessidades e gostos, para poder desenvolver as estratégias de marketing territorial mais adequadas.

\section{Enoturismo em Portugal: uma visão de síntese}

Portugal é o quinto maior produtor de vinho da União Europeia e, no contexto do comércio internacional, tanto a nível europeu como mundial, os vinhos nacionais têm um papel de destaque. O país é rico em regiões vitivinícolas de norte a sul, percebendo-se a grande importância que o setor vitivinícola tem na sua economia (Costa e Dolgner, 2003). Não foi seguramente por acaso que na década de 90 do século passado, o economista Michael Porter elegeu o setor como um dos eixos que, sendo estruturador do seu modelo de desenvolvimento económico para Portugal, pelo seu carácter tradicional, necessitava de um esforço significativo para se reinventar.

Embora se possa dizer que o enoturismo em Portugal teve início nos anos 50, através de visitas às caves do vinho do Porto (Inácio e Cavaco, 2010), as primeiras rotas do vinho 5 surgiram apenas em 1993, com a participação do país no programa Dyonisios promovido pela União Europeia (Simões, 2008). Em bom rigor, aliás, estas só entraram em funcionamento entre 1996 e 1998, aquando da sua dinamização pelas Comissões Vitivinícolas Regionais e pelas Regiões de Turismo, existindo hoje, segundo o site oficial do Instituto da Vinha e do Vinho, 11 rotas do vinho em funcionamento ${ }^{6}$.

\footnotetext{
5 "Sistema integrado de relações entre o turismo e as indústrias vinícolas, por meio do qual os turistas podem se conectar à oferta turística de uma região vitícola" (Ungureanu, 2015, p. 196).

6 Rota dos Vinhos Verdes, Rota dos Vinhos da Bairrada, Rota da Vinha e do Vinho do Oeste, Rota da Vinha e do Vinho do Ribatejo, Rota dos Vinhos de Bucelas, Carcavelos e Colares, Rota dos Vinhos da Península de Setúbal Costa Azul, Rota dos Vinhos do Alentejo, Rota dos Vinhos da Beira Interior, Rota dos Vinhos de Cister, Rota dos Vinhos do Porto e Rota do Vinho do Dão.
} 
Mais recentemente, o enoturismo foi identificado na Estratégia Turismo 2027 como um dos 10 produtos estratégicos para o desenvolvimento do turismo em Portugal. Criou-se mesmo um Programa de Ação para o Enoturismo em Portugal 2019-2021, que integra projetos aprovados com um investimento total superior a 60 milhões de euros, financiados nomeadamente pela Linha de Apoio à Valorização Turística do Interior, a Linha de Apoio ao Turismo Acessível e o Sistema de Incentivo à Inovação Empresarial - Produtiva. Realizaramse vários investimentos em unidades de enoturismo com o objetivo de melhorar as condições de produção e de experiência turística, nomeadamente em hotéis temáticos, rotas, adegas, enotecas, alojamento quintas e solares, eventos e museus. Um estudo realizado em 2016 pela Associação das Rotas do Vinho de Portugal7 , refere a existência 250 adegas, 850 quintas produtoras, 76 caves e 1200 produtores vitivinícolas no país (Novais e Antunes, 2009).

Embora, como ficou bem patente, Portugal reúna algumas das condições necessárias para desenvolver o enoturismo (ex: capacidade instalada, história, tradição e cultura), Pina (2010) evidencia a falta de cooperação, planeamento, monitorização e organização da oferta enoturística, sublinhando que o sucesso do enoturismo português terá de passar pela definição de um master plan que integre uma estratégia transversal, para todos os destinos do país; será necessária assim uma cooperação não só entre os setores vitivinícola, turístico e a comunidade, como o envolvimento de organismos oficiais e o desenvolvimento de políticas regionais e nacionais específicas.

\section{Reguengos de Monsaraz, Cidade Europeia do Vinho 2010}

\subsection{Contexto sócio territorial}

O concelho de Reguengos de Monsaraz localiza-se no Sul de Portugal continental mais concretamente na região do Alentejo, sub-região do Alentejo Central, distrito de Évora, ocupa uma área $461 \mathrm{~km}^{2}$, tem cerca de 11 mil habitantes, uma densidade populacional de 23 habitantes por $\mathrm{Km}^{2}$ e, desde tempos muito remotos, a cultura da vinha e do vinho encontram-se ligados à sua identidade.

7 Associação das Rotas dos Vinhos de Portugal. Disponível em http://rotadosvinhosdeportugal.pt. Acesso em: 4 de abril de 2020. 
O município é conhecido pela sua produção vitivinícola e pela qualidade dos vinhos produzidos, assumindo estas atividades grande peso no desenvolvimento socioeconómico do concelho e na sua dinamização, como reflete o número de adegas existentes (Figura 1) e a produção de vinho do município, que representa mais de $1 / 4$ do total da produção do distrito de Évora na campanha 2019/2020, fazendo de Reguengos o concelho com maior produção vitivinícola desta região do Alentejo.

AC - Adega do Calisto

AJS - Adega Josẻ de Sousa

CRM - Cooperativa Agrícola de Reguengos de Monsaraz

ERV - Ervideira

ESP - Esporão

EV - Elite Vinhos

LDV - Luis Duarte Vinhos

MP - Monte dos Perdigões

MS - Monte das Serras

SLB - São Lourenço do Barrocal

Freguesias do concelho de Reguengos de Monsaraz

Freguesia do concelho de Évora

Figura 1- Adegas de Reguengos de Monsaraz registadas na Comissão Vitivinícola.

Fonte: Elaborado pelos autores

No ano de 2018, o concelho recebeu 98447 turistas, dos quais cerca de 50 mil visitaram as adegas e enoturismos do município. As maiores adegas adaptaram-se a esta realidade e a quantidade de estabelecimentos ligados ao enoturismo aumentou significativamente, surgindo ainda um elevado número de agentes turísticos promotores de visitas guiadas a produtores regionais.

A Rota dos Vinhos do Alentejo, da qual Reguengos de Monsaraz faz parte, é o rosto da prática do enoturismo, assim como a referência do turismo na região e surgiu em 1997 para dar a conhecer e promover os vinhos regionais, fomentar o contacto entre o produtor e o 
consumidor, criar laços e divulgar os vinhos da região (Silva, 2012). Esta era inicialmente composta por três rotas temáticas (Rota Histórica, Rota do Guadiana e Rota de S. Mamede) que, em 2011, se reorganizaram e agregaram numa única rota. Abrange oito áreas de Denominação de Origem Controlada (DOC), nomeadamente, Amareleja/Granja, Borba, Évora, Moura, Portalegre, Redondo, Reguengos de Monsaraz e Vidigueira. Segundo o site oficial da Comissão Vitivinícola Regional Alentejana ${ }^{8}$, com a Rota dos Vinhos do Alentejo pretende-se incentivar os potenciais turistas motivados pelo vinho para outros aspetos da realidade cultural e turística regional (património edificado, artesanato, animação turística e cultural, gastronomia). O número de adegas que integram esta rota tem aumentado ao longo dos anos, correspondendo atualmente a 72 . Saliente-se que na sede da Rota dos Vinhos do Alentejo se podem realizar provas de vinho, vender vinho, marcar visitas às adegas e obter informações de carácter enoturístico (Silva, 2012).

Durante o período de vigência do Quadro de Referência Estratégica Nacional (QREN 2007/2013), o município definiu que a sua estratégia estaria assente na vitivinicultura e no turismo, enquanto motores económicos locais. Com a aprovação do Plano Regional de Ordenamento do Território do Alentejo (PROTA), em 2010, que definiu os vetores estratégicos de centralidade para cada concelho da região, Reguengos conseguiu aplicar as suas ideias e criar uma vertente vitivinícola. No entanto, embora a estratégia política pretendida pela autarquia tenha sido oficializada no PROTA, a sua aplicação só se concretizou no Programa Portugal 2020. Foi neste contexto, que surgiu a ideia da candidatura de Reguengos de Monsaraz a CEV2015 como um instrumento adequado para materializar a estratégia política definida para o período de vigência do QREN2007/2013.

Esta candidatura, surgida em parceria com as cidades de Évora e Elvas, de modo a beneficiar do facto de ambas terem sido classificadas como Património da Humanidade pela UNESCO, foi submetida em 2014 e aprovada pela RECEVIN nesse mesmo ano, tendo uma duração prevista de 16 meses (de novembro de 2014 a fevereiro de 2016).

O arranque oficial deu-se com a cerimónia de abertura, em fevereiro de 2015 , delineada e realizada pelo município de Reguengos, na qualidade de promotor principal, em conjunto com os 120 parceiros que se associaram à iniciativa integrando produtores de vinho e

8 Comissão Vitivinícola Regional Alentejana. Disponível em https://www.vinhosdoalentejo.pt/. Acesso em: 24 de abril de 2020 . 
outros agentes estratégicos (entidades públicas e privadas, estabelecimentos de ensino e hotelaria). Os fatores que orientaram esta iniciativa foram "a necessidade de um instrumento de estratégia política, a importância do setor vitivinícola para a economia do município, o aumento da competitividade entre municípios e a existência de um património diversificado no município" (Bento, 2017). O município assumiu que seriam disponibilizados os recursos necessários para a implementação da CEV2015, bem como o total apoio de todos os envolvidos e seria, ainda, criada uma equipa multidisciplinar de acompanhamento da mesma.

Reguengos de Monsaraz encarou esta iniciativa como um instrumento estratégico útil para reconhecer o seu património edificado, natural e imaterial, a identidade cultural das suas gentes e promover, nacional e internacionalmente, os vinhos e a imagem da região, através da articulação entre turismo, indústrias culturais e viticultura.

Para além destes aspetos, de acordo com a autarquia, os principais motivos pelos quais a cidade deveria ser eleita como CEV2015 prendiam-se com a existência de um plano de atividades culturalmente rico e diversificado, de fontes de financiamento assentes em parcerias públicas e privadas, de um elevado interesse turístico (megalitismo, gastronomia, artesanato e paisagens ímpares), da produção vitivinícola reconhecida nacional e internacionalmente, da aposta da região Alentejo como a melhor região de enoturismo do Mundo e da possibilidade de estruturação e desenvolvimento do território.

\subsection{Rede Europeia de Cidades do Vinho e Iniciativa Cidade Europeia do Vinho}

A RECEVIN é uma associação constituída por cidades ou grupos de produtores de vinho localizados em áreas de denominação de vinho de qualidade na Europa que surgiu, em 2000, com o intuito de defender os interesses dos territórios cuja economia e cultura estão associadas ao vinho. Esta associação integra cerca de 800 cidades $^{3}$ europeias de 11 países (Alemanha, Áustria, Bulgária, Eslovénia, Espanha, França, Grécia, Hungria, Itália, Portugal e Sérvia). Para o período de 2016 a 2020 a Associação de Municípios Portugueses do Vinho detém a presidência desta organização, através do município associado de Reguengos de Monsaraz. O principal objetivo da RECEVIN é a valorização das cidades onde a viticultura tem especial relevância, tanto no âmbito produtivo e empresarial como ao nível 
sociocultural. Para alcançar este objetivo, a RECEVIN promove inúmeras atividades, com destaque para a iniciativa CEV, concurso internacional iniciado em 2012, que já premiou várias cidades (Figura 2).

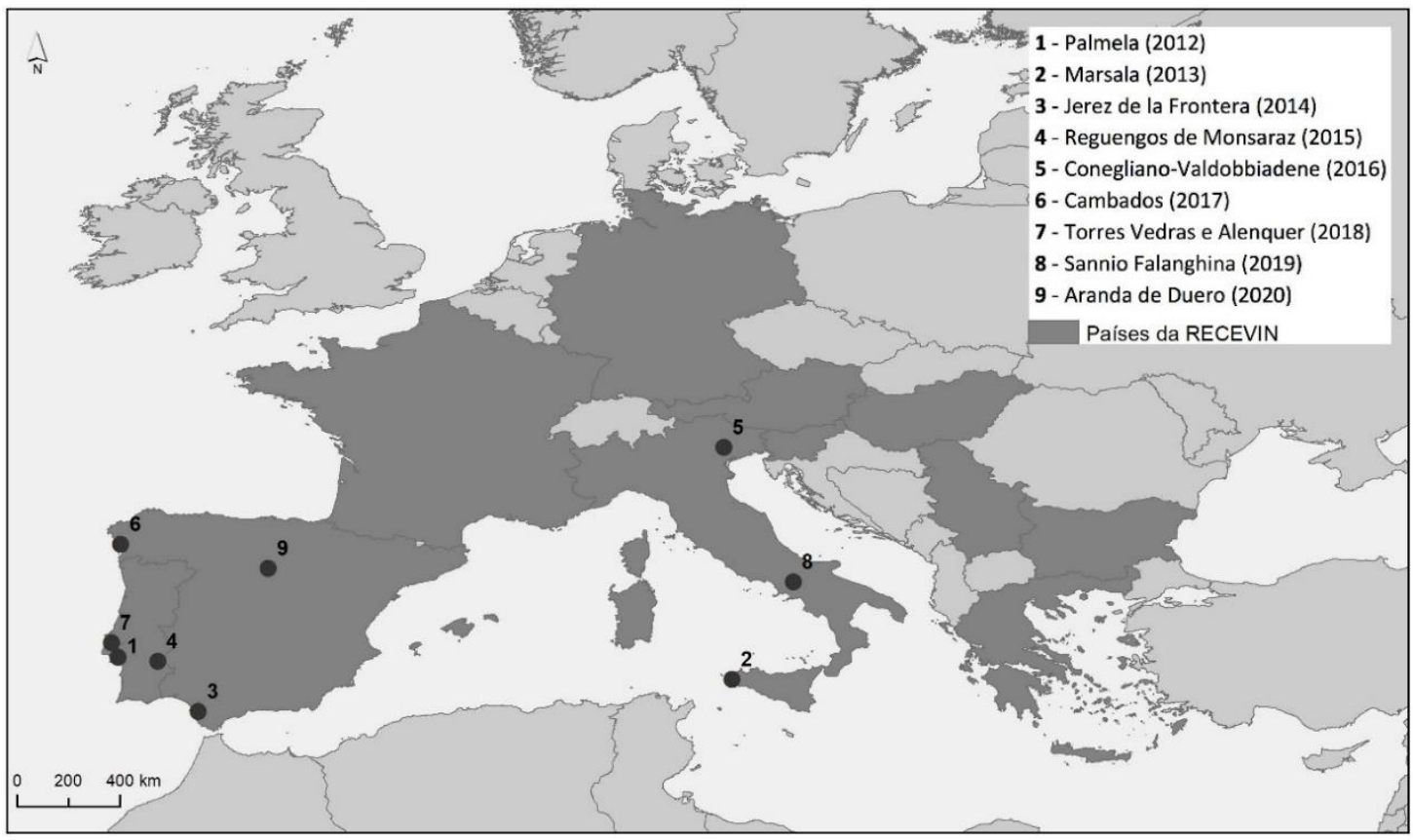

Figura 2 - Cidades eleitas como Cidade Europeia do Vinho.

Fonte: Elaborado pelos autores

Espera-se, em torno desta iniciativa, um impacto positivo, em termos sociais e económicos, que se reflita na qualidade de vida da população local. Um dos seus principais objetivos é aproveitar esta designação para elevar o perfil das cidades, a nível nacional e internacional, através da programação de uma série de eventos e atividades culturais em torno do vinho. Outros objetivos a registar prendem-se com o aumento da notoriedade dos vinhos da região, o incremento do fluxo turístico e da visibilidade externa da região, a valorização da identidade cultural e patrimonial locais, a promoção da região e do seu desenvolvimento económico a participação do máximo número de agentes económico-sociais do território e a consolidação dos vínculos entre essa região e as restantes regiões europeias de vinho. A CEV pretende ser catalisadora de dinâmicas de desenvolvimento económico e de emprego, procurando a sustentabilidade e qualidade de vida dos cidadãos.

A candidatura das cidades concorrentes deve incluir obrigatoriamente a organização da Gala CEV, do dia do Enoturismo e do estágio RECEVIN para jovens viticultores. As cidades interessadas devem ser membros da RECEVIN e da Associação Nacional de Vinhos (que em 
Portugal é a AMPV $^{9}$ ), apresentar um dossier com um programa cultural envolvendo representantes de outros países da rede que se baseie na cooperação entre todos os atores envolvidos. As candidaturas são enviadas para a Secretaria Geral da RECEVIN, em Barcelona, apresentadas posteriormente em Conselho de Administração para apreciação e, consequente, eleição da CEV para o ano seguinte. A candidatura poderá ser apresentada em conjunto com outras cidades. Após cada ano de CEV, deverá ser elaborado um relatório de avaliação dos resultados do evento, tendo em consideração as atividades desenvolvidas, incluindo indicadores de participação e as suas implicações ao nível local e internacional.

\subsection{Impactos locais em Reguengos de Monsaraz: atividades, investimento e perceção dos atores locais}

Em Reguengos de Monsaraz, durante o período CEV, realizaram-se mais de uma centena de eventos, cerca de metade dos quais planificados e apresentados no Dossier de Candidatura a CEV2015 (Tabela 2). Para além destes, ocorreram espetáculos culturais, realizaram-se ações diplomáticas, participou-se em feiras nacionais e internacionais e organizaram-se colóquios e conferências, com o objetivo de reforçar o reconhecimento nacional e internacional da região e dos seus vinhos. De modo a fortalecer a sua capacidade de intervenção e a projeção das atividades desenvolvidas, o município elaborou ainda um Plano de Merchandising Institucional e um Plano de Promoção Institucional CEV2015.

O orçamento, estimado e apresentado na candidatura, para a concretização da CEV2015, foi de um milhão de euros, tendo Reguengos de Monsaraz procurado fontes de financiamento junto de diversas entidades públicas, privadas e associações ${ }^{10}$. No momento da candidatura, em 2014, as dúvidas relativas às referidas fontes constituíram uma situação de risco financeiro e o investimento foi canalizado através do orçamento municipal para 2015. As principais fontes de financiamento foram Évora e Elvas (que haviam integrado a candidatura a CEV2015), a Entidade Regional de Turismo do Alentejo e Ribatejo e vários produtores de vinho do concelho.

9 Associação de Municípios Portugueses do Vinho. Disponível em http://ampv.pt/. Acesso em: 4 de abril de 2020.

10 Lamentavelmente, o Balanço das atividades da CEV2015 é omisso relativamente à execução orçamental, inviabilizando qualquer análise sobre esta matéria. 
Tabela 2 - Eventos apresentados no Dossier de Candidatura a CEV2015.

\begin{tabular}{|c|c|}
\hline Tipologia dos Eventos & Eventos \\
\hline Alojamento e Gastronomia & $\begin{array}{l}\text { Encontro Europeu de Confrarias Enogastronómicas; } \\
\text { Festival do Lagostim. }\end{array}$ \\
\hline Cultura & $\begin{array}{l}\text { Conferência "O Arquétipo do vinho da região de Reguengos de Monsaraz; } \\
\text { Congresso do Vinho e da Vinha; } \\
\text { Congresso Internacional das Polifonias; } \\
\text { Exposição de Astrofotografia; } \\
\text { Feira do Livro; } \\
\text { Festa do Cante; } \\
\text { Outubro mês da Música. }\end{array}$ \\
\hline Desporto & $\begin{array}{l}\text { Ladeira do Berço; } \\
\text { Passeio TT Rota do Vinho; } \\
\text { Vinhos Ervideira Rali TT; } \\
\text { I Trail Running; } \\
\text { VI Maratona BTT- Piranha do Alqueva. } \\
\end{array}$ \\
\hline $\begin{array}{l}\text { Feiras de atividades } \\
\text { económicas e culturais }\end{array}$ & $\begin{array}{l}\text { EXPOREG; } \\
\text { Feira de S. Mateus (Elvas); } \\
\text { Festa Ibérica da Olaria e do Barro; } \\
\text { 35a FATACIL (Lagoa). }\end{array}$ \\
\hline $\begin{array}{l}\text { Festas, Celebrações e } \\
\text { Cerimónias }\end{array}$ & $\begin{array}{l}\text { Cante ao Menino; } \\
\text { Gala da Cidade Europeia do Vinho; } \\
\text { Festas de Santo António; } \\
\text { Festas em Honra de Nosso Senhor dos Paços. }\end{array}$ \\
\hline Observações astronómicas & Dark Sky Alqueva. \\
\hline Promoção e Divulgação & $\begin{array}{l}\text { Ação de promoção e divulgação na ANA; } \\
\text { Divulgação em canais de televisão; } \\
\text { Promoção de Reguengos de Monsaraz, CEV2015; } \\
\text { Promoção de Reguengos de Monsaraz, CEV2015 no Parlamento Europeu; } \\
\text { Visita de jornalistas e líderes de opinião. }\end{array}$ \\
\hline Turismo & $\begin{array}{l}\text { Bolsa de Turismo de Lisboa 2015; } \\
\text { Sinalização turística. }\end{array}$ \\
\hline Vinhos e Enologia & $\begin{array}{l}\text { Atividades vínicas para turistas na CARMIM; } \\
\text { Comemoração do Dia Europeu do Enoturismo 2015; } \\
\text { Estágio da RECEVIN para jovens viticultores europeus; } \\
\text { Feiras internacionais e nacionais; } \\
\text { Formação na área dos vinhos; } \\
\text { Fins de semana temáticos com restaurantes; } \\
\text { Moon Harvest Dark Sky Alqueva; } \\
\text { Observação astronómica com provas de vinho; } \\
\text { Passeios de barco no Alqueva com provas de vinho; } \\
\text { Tasting tours; } \\
\text { "Vinho com Arte" }\end{array}$ \\
\hline
\end{tabular}

Fonte: Elaborado pelos autores a partir do Dossier de Candidatura de Reguengos de Monsaraz a CEV2015

No que toca às perceções dos atores locais, com exceção de um único produtor local, todos os produtores de vinho inquiridos atribuíram à iniciativa CEV2015 uma importância muito elevada. Não obstante, as perspetivas apresentadas são bastante diversificadas, evidenciando-se um conjunto de benefícios relacionados essencialmente com a atratividade e a exposição do vinho, mas também se referem necessidades e até debilidades que, 
efetivamente, põem a nu alguns dos principais problemas sentidos pelos produtores vitivinícolas entrevistados (Tabela 3).

Tabela 3 - Benefícios, Necessidades e Debilidades da CEV2015 para os produtores de vinho do concelho de Reguengos de Monsaraz.

\begin{tabular}{|c|c|c|}
\hline Benefícios & Necessidades & Debilidades \\
\hline $\begin{array}{l}\text { Projeção internacional e } \\
\text { nacional da marca e dos } \\
\text { vinhos; } \\
\text { Contactos com novos } \\
\text { players internacionais; } \\
\text { Aumento das vendas. }\end{array}$ & $\begin{array}{l}\text { Aumento da oferta de Enoturismo; } \\
\text { Aumento da capacidade de } \\
\text { divulgação; } \\
\text { Captação de mão-de-obra para as } \\
\text { ações desenvolvidas. }\end{array}$ & $\begin{array}{l}\text { Nem sempre era possível } \\
\text { participar em todos os eventos e } \\
\text { atividades, por não estarem } \\
\text { exclusivamente dedicados à } \\
\text { iniciativa CEV2015; } \\
\text { Falta de recursos materiais e/ou } \\
\text { humanos. }\end{array}$ \\
\hline
\end{tabular}

Fonte: Elaborado pelos autores

Os impactos provocados no município de Reguengos de Monsaraz, pela iniciativa CEV5015, acompanham os impactos gerais do enoturismo, enunciados anteriormente. Para além da promoção e fidelização da marca e dos vinhos, único impacto que se "verificou muito" em todas as adegas, assinalaram-se outros, com grande intensidade, na atração de novos mercados, no aumento das vendas gerais e dos lucros e no aumento das visitas ao enoturismo. Saliente-se que, no entender dos produtores, não se sentiram alterações no aumento das vendas diretas, isto é, aquelas que são feitas aos enoturistas, bem como na perda de propriedade das vinhas e na poluição e deterioração dos terrenos agrícolas. Importa ainda referir um conjunto de impactos, ao nível da criação de novas parcerias, da obtenção de novas fontes de rendimento e de novos investimentos e da possibilidade de testar e comercializar novos produtos, que se manifestaram, de forma moderada, nas diferentes adegas.

Os munícipes atribuíram à iniciativa CEV2015, um grau de importância muito elevado, pelo facto de esta ter criado uma dinâmica local, nacional e internacional, promovendo o vinho integrado no território e dando maior visibilidade ao concelho. No entanto, os impactos percecionados não foram sentidos da mesma forma por todos (Tabela 4). Relativamente aos impactos de efeito positivo para o município salientam-se a atenuação da sazonalidade turística, o aumento do número de turistas, sobretudo, de outras nacionalidades, a consolidação da marca de Reguengos de Monsaraz, a criação de novos eventos e a 
incrementação do consumo de produtos locais. O aumento do gasto médio por visitante, a captação de investimentos, a criação de empregos, o contacto com turistas, a preservação e valorização dos valores culturais e a promoção da sustentabilidade ambiental merecem também destaque.

Os resultados mostram que a perceção dos munícipes incide sobre um conjunto diversificado de impactos relacionados com a atividade turística cujos efeitos são essencialmente de natureza económica. Em termos culturais, é interessante verificar a coexistência de dinâmicas de abertura ao exterior e ao "outro" (atração e contacto com turistas), com uma certa capacidade de preservação daquilo que é visto como tradicional e autêntico. Aparentemente, duas tendências que muitas vezes surgem como mutuamente exclusivas, configuram, na opinião dos munícipes de Reguengos de Monsaraz, aquilo a que poderíamos, com alguma propriedade, designar "localismo cosmopolita". O facto de, como abaixo se verá, não se ter verificado qualquer perda de identidade local na opinião dos respondentes, apenas reforça este entendimento.

Quanto aos impactos negativos importa referir o aumento do tráfego e a sobrecarga turística. Por outro lado, para a maioria dos munícipes, alguns dos impactos mais habituais no quadro de processos de desenvolvimento do enoturismo, tais como a deterioração das condições de emprego, a exclusão social, a marginalização dos habitantes e perda de identidade local, não se verificaram de todo.

Também a este nível os resultados são contrastantes. Por um lado, os impactos de natureza socioeconómica mencionados não tiveram qualquer expressão e isso não pode deixar de ser encarado como um resultado francamente positivo de todo este processo. No entanto, por outro lado, o facto de se ter verificado um aumento do tráfego e da sobrecarga turística, ainda que de forma não tão acentuada como outros impactos, indicia que o município poderia ter-se debruçado mais sobre estas dimensões, sobretudo tendo em conta que se trata de impactos fundamentais para a viabilidade e sustentabilidade de processos de desenvolvimento gerados, induzidos ou alavancados pela CEV2015. 
Tabela 4 - Impactos da CEV2015 percecionados pelos atores locais do concelho de Reguengos de Monsaraz (\%).

\begin{tabular}{|c|c|c|c|c|}
\hline Impactos & $\begin{array}{c}\text { Não se } \\
\text { verificou }\end{array}$ & Verificou-se pouco & $\begin{array}{c}\text { Verificou-se } \\
\text { moderadamente }\end{array}$ & $\begin{array}{c}\text { Verificou-se } \\
\text { muito }\end{array}$ \\
\hline Atenuação da sazonalidade turística & 0 & 0 & 33 & 67 \\
\hline Atração turistas de outras nacionalidades & 0 & 0 & 16 & 84 \\
\hline Aumento do gasto médio por visitante & 0 & 0 & 78 & 22 \\
\hline Aumento do número de turistas & 0 & 0 & 10 & 90 \\
\hline Aumento do tráfego & 0 & 10 & 25 & 65 \\
\hline Captação de novos investimentos & 0 & 16 & 51 & 33 \\
\hline $\begin{array}{l}\text { Consolidação e promoção da imagem de } \\
\text { Reguengos de Monsaraz }\end{array}$ & 0 & 0 & 8 & 92 \\
\hline Criação de novos empregos & 0 & 12 & 88 & 0 \\
\hline Criação de novos eventos e atividades & 0 & 0 & 22 & 78 \\
\hline $\begin{array}{l}\text { Criação ou melhoria de infraestruturas e/ } \\
\text { ou serviços }\end{array}$ & 16 & 39 & 45 & 0 \\
\hline Degradação dos caminhos/estradas & 59 & 27 & 14 & 0 \\
\hline Descontrolo da procura e comercialização & 16 & 45 & 39 & 0 \\
\hline Deterioração das condições de emprego & 82 & 18 & 0 & 0 \\
\hline Enriquecimento cultural & 27 & 47 & 20 & 6 \\
\hline Especulação imobiliária & 41 & 51 & 8 & 0 \\
\hline Exclusão social & 86 & 14 & 0 & 0 \\
\hline Experiência e contacto com turistas & 0 & 12 & 59 & 29 \\
\hline $\begin{array}{l}\text { Incrementação do consumo de produtos } \\
\text { locais }\end{array}$ & 0 & 0 & 14 & 86 \\
\hline Marginalização dos habitantes & 96 & 4 & 0 & 0 \\
\hline Perda de identidade local & 94 & 6 & 0 & 0 \\
\hline $\begin{array}{l}\text { Preservação e valorização dos valores } \\
\text { culturais, das tradições, da autenticidade } \\
\text { e identidades locais }\end{array}$ & 0 & 0 & 78 & 22 \\
\hline Promoção da sustentabilidade ambiental & 0 & 0 & 84 & 16 \\
\hline $\begin{array}{l}\text { Revitalização de atividade económicas } \\
\text { tradicionais }\end{array}$ & 0 & 45 & 39 & 16 \\
\hline Sobrecarga turística & 0 & 16 & 27 & 57 \\
\hline
\end{tabular}

Fonte: Elaborado pelos autores

Nota: para cada uma das categorias de resposta, são destacados os três valores mais elevados 
A entrevista realizada com o Presidente da Câmara sugere que a iniciativa CEV2015 foi importante por envolver diversas variáveis e questões relacionadas com o surgimento de novas adegas e estabelecimentos de enoturismo, com encomendas concretas de alguns mercados, com a notoriedade interna e externa da sub-região vitivinícola de Reguengos de Monsaraz e com o aumento do número de turistas, principalmente estrangeiros. Revela ainda que a iniciativa permitiu consolidar a imagem e identidade do município, constituindo um instrumento de desenvolvimento local, que, nas palavras deste líder autárquico: "foi um projeto que personificou e personifica, ainda hoje, pelas consequências que teve, as prioridades que temos em qualquer questão de gestão territorial local e de desenvolvimento económico sustentável que assenta nos motores económicos sem prejuízo de novas oportunidades de empreendedorismo." Como principais dificuldades, aponta o acesso a fundos comunitários e, internamente, a gestão dos recursos humanos, já que os funcionários tiveram de acumular o trabalho normal de funcionamento da autarquia com o acompanhamento das atividades associadas à iniciativa CEV2015.

Na sequência desta iniciativa foi possível marcar presença em vários fora Internacionais, reforçando a importância estratégica da CEV2015, permitindo que Reguengos de Monsaraz se afirmasse como um município com capacidade de integração em diversos projetos de âmbito europeu, com outras áreas de incidência (ex: COSME, Europe for Citizens, ERASMUS, LIFE).

Para Bento (2017), a iniciativa CEV2015 constituiu um projeto inovador em Reguengos de Monsaraz, pois foi a primeira grande intervenção que, sem ser uma obra pública, envolveu toda a comunidade, tornando-se assim no primeiro grande conjunto de ações imateriais que valorizam um produto endógeno - o vinho.

A CEV2015 permitiu à autarquia compreender melhor a importância que o enoturismo apresenta para o desenvolvimento local, levando-a a adotar novas políticas e estratégias de divulgação e marketing territorial, assentes nesta atividade. Esta iniciativa foi o início de um processo que pretende a promoção de Reguengos de Monsaraz como um destino enoturístico de grande valor e interesse, para o que se apostou numa estratégia de continuidade da CEV2015 em torno de duas linhas orientadoras: o registo da marca Capital dos Vinhos Portugal (CVP) e a aposta na Rota dos Vinhos do Alentejo. A marca Reguengos de Monsaraz - CVP foi registada junto do Instituto de Registo de Propriedade Industrial em 
2016 e apresentada na Bolsa de Turismo de Lisboa, com o intuito de criar uma marca que valorizasse os vinhos produzidos localmente e desse a conhecer a gastronomia, enoturismo e património da região. Outra forma de materialização do Projeto CEV2015, passou pela eleição do Presidente da Câmara de Reguengos como Presidente da RECEVIN, em abril de 2016, durante a Assembleia Geral da RECEVIN, em Valdobbiadene, traduzindo também, mesmo que apenas a um nível simbólico, a importância do trabalho desenvolvido por este município alentejano.

\section{Considerações Finais}

A iniciativa CEV 2015, promovida pela RECEVIN, uniu um conjunto de entidades públicas e privadas com o interesse comum de aumentar a notoriedade do concelho de Reguengos, dos seus produtores de vinho e dos enoturismos regionais. Neste processo, não se olhou apenas para o vinho, mas também para todos os valores turísticos que caracterizam o município, nomeadamente o Alqueva, o artesanato, a vila medieval de Monsaraz, o cante alentejano e a gastronomia. Desta forma, a CEV2015 revelou-se um instrumento fundamental para recentrar o processo de desenvolvimento de Reguengos de Monsaraz em torno do enoturismo e atividades conexas, permitindo à autarquia contextualizar, perceber e valorizar o verdadeiro motor da economia do município, ao mesmo tempo que promove um maior grau de consciencialização da importância do enoturismo para o desenvolvimento local.

Foram vários os impactos da iniciativa no município de Reguengos de Monsaraz, tanto a nível económico, como social e cultural não sendo, no entanto, percebidos da mesma forma pelos diferentes atores locais. Enquanto para os produtores de vinho se registaram maioritariamente impactos positivos, o mesmo não sucede quando se trata da perceção dos munícipes que, efetivamente, colocaram em evidência alguns impactos negativos importantes, aparentemente, não devidamente acautelados pelo município aquando da conceção da candidatura. Neste sentido, as evidências sugerem que nem tudo correu bem ao nível do envolvimento significativo da comunidade em todas as fases do processo de elaboração de uma candidatura que, efetivamente parece ter sido produzida numa lógica eminentemente top-down, pouco colaborativa e com défice de apropriação pela 
comunidade local. Não será por acaso, aliás, que aspetos como a sobrecarga turística, a pouca revitalização económica de atividades tradicionais e, sobretudo, o pouco impacto da CEV2015 ao nível do enriquecimento cultural foram evidenciados pelos inquiridos. É importante, pois, que o município procure envolver mais a comunidade local, criando estratégias participativas substantivas e consequentes, de modo a tornar mais consistente e sustentável a estratégia de desenvolvimento ancorada no enoturismo que tem vindo a implementar.

\section{Referências Bibliográficas}

Abreu, E. \& Costa, L.P.C. (2002). Turismo e Vinho - Um brinde ao Enoturismo. Jornal Publituris, 29.

Bento, M. (2017). Inovação na Política Pública em Reguengos de Monsaraz: Implementação do Projeto CEV 2015. Dissertação de Mestrado em Políticas Públicas e Projetos. Escola de Ciências Sociais, Universidade de Évora.

Braga, T. M. (2002). Desenvolvimento Local Endógeno. Estudos Urbanos e Regionais, 5, pp. 23-37.

Brás, J. (2010). As rotas do vinho como elemento de desenvolvimento económico. Dissertação de Mestrado em Planeamento do Território - Inovação e Políticas de Desenvolvimento. Secção Autónoma de Ciências Sociais, Jurídicas e Políticas, Universidade de Aveiro.

Byrd, E.T., Canziani, B., Hsieh, Y.C., Debbage, K. \& Sonmez, S. (2016). Wine tourism: Motivating visitors through core and supplementary services. Tourism Management, 52, pp. 19-29.

Carlsen, J. (2004). A review of global wine tourism research. Journal of Wine Research, 15, pp. 5-13.

Charteres, S. \& Ali-Knight, J. (2002). Who is the wine tourist?. Tourism Management, 23, pp. 311-319.

Costa, A. \& Dolgner, M. (2003). Enquadramento Legal do Enoturismo. Escola Superior de Tecnologia e Gestão, Instituto Politécnico da Guarda.

Getz, D., Dowling, R., Carlsen, J. \& Anderson, D. (1999). Critical Success Factors for Wine Tourism. International Journal of Wine Marketing, 11, 3 ABI/Inform Global, pp. 20- 43.

Getz, D. (2000). Explore wine tourism: Management, Development \& Destinations. Cognizant Communication Corporation. Elmsford.

Hall. M.; Cambourne, B.; Macionis, N. e Johnson, G. (1997), "Wine Tourism and network development in Australia and New Zealand: review, establishment and prospects", International Journal of Wine Marketing, 9, pp. 5-3.

Hall, C.M. \& Macionis, N. (1998). Wine tourism in Australia and New Zealand. Em: R.W. Buttler., C.M. Hall. \& J.M. Jenkins (eds), Tourism and Recreation in Rural Areas. John Wiley and Sons, London, pp. 267-298.

Hall, C.M. (2000). Wine Tourism in the Mediterranean: A Tool for Restructuring and Development. Thunderbird International Business Review, 42, pp. 445- 465.

Hall, C. M., Johnson, G., \& Mitchell, R. (2000). Wine tourism and regional development. Em: C.M. Hall., L. Sharples., B. Cambourne. \& N. Macionis (eds), Wine Tourism Around the World Development Management and Markets. Routledge, pp. 196-225

Inácio, A. I. (2008). O Enoturismo em Portugal: da "cultura" do vinho ao vinho como cultura: a oferta enoturística nacional e as suas implicações no desenvolvimento local e regional. Dissertação de Doutoramento em Geografia e Planeamento Regional e Urbano, Faculdade de Letras da Universidade de Lisboa. 
Inácio, A. I. \& Cavaco, C. (2010). Enoturismo em Portugal: forma de desenvolvimento regional e afirmação cultural local. Revista Turismo \& Desenvolvimento, №13/14, pp. 761-769.

Instituto do Turismo de Portugal. (2017). Estratégia 2027. Estratégia Turismo 2027. Lisboa.

Lucena, E. (2017). Avaliação do Impacto da Iniciativa-Reguengos de Monsaraz, Cidade Europeia do Vinho 2015. Dissertação de Mestrado em Ciências do Consumo Alimentar. Universidade de Évora.

Município de Reguengos de Monsaraz. (2014). Dossier de Candidatura da Cidade de Reguengos de Monsaraz a Cidade Europeia do Vinho. Município de Reguengos de Monsaraz.

Município de Reguengos de Monsaraz. (2016). Balanço das atividades Cidade Europeia do Vinho 2015. Município de Reguengos de Monsaraz.

Novais, C. \& Antunes, J. (2009). O contributo do enoturismo para o desenvolvimento regional: O caso das Rotas dos Vinhos. 15o Congresso da Associação Portuguesa do Desenvolvimento Regional, 6 a 11 de Julho de 2009. Cidade da Praia.

Nunes, R. (2018). Gestão Estratégica de um Destino Turístico: Torres Vedras. Cidade Europeia do Vinho 2018. Relatório de Estágio em Turismo, Território e Patrimónios. Faculdade de Letras, Universidade de Coimbra.

Pina, A.J. (2010). Estratégias de marketing para o enoturismo português. Cogitur - Journal of Tourism Studies, 3, pp. 21-38.

Rede Europeia de Cidades do Vinho (2014). Regulamento de Participação do Concurso Cidade Europeia do Vinho. Rede Europeia de Cidades do Vinho.

Silva, S. (2012). Enoturismo no Alentejo - Visão Global e Perspectivas de Desenvolvimento. Dissertação de Mestrado em Turismo, Especialização em Gestão Estratégica de Destinos Turísticos. Escola Superior de Hotelaria e Turismo do Estoril.

Simões, O. (2008). Enoturismo em Portugal: as Rotas de Vinho. Revista de Turismo y Patrimonio Cultural, 6, pp. 269-279.

Skinner, A. (2000). Napa valley, California: a model of wine region development. Em: C.M. Hall., L. Sharples., B. Cambourne. \& N. Macionis. (eds), Wine Tourism Around the World, Butterworth-Heinemann, Oxford, pp.283296.

Ungureanu, M. (2015). Wine road - an instrument for the valorisation of wine tourism potential Case study: Alba county vineyards. Analele Universităţii Din Oradea - Seria Geografie, 5(2).

Var, T.; Kaplan, M. D. \& Yurt, O. (2006). Challenges and Opportunities of Developing Wine Tourism in a Small Community in Turkey. E-Review of Tourism Research, Vol. 4, №1, pp.9-18.

Williams, P (2001). Positioning wine tourism destinations: an image analysis. International Journal of Wine Marketing, 13. 